\title{
OPEN Author Correction: Virtual clinical trials identify effective combination therapies in ovarian cancer
}

\section{Emilia Kozłowska, Tuulia Vallius, Johanna Hynninen ${ }^{\circledR}$, Sakari Hietanen, Anniina Färkkilä \& Sampsa Hautaniemi}

Correction to: Scientific Reports https://doi.org/10.1038/s41598-019-55068-z, published online 10 December 2019

This Article contains a typographical error in the Acknowledgements section.

“This project has received funding from the European Union's Horizon 2020 Research and Innovation Programme under grant agreement No. 66740, the Academy of Finland, the Sigrid Jusélius Foundation, Finnish Cancer Associations and by National Science Centre, Poland (http://ncn.gov.pl), grant DEC 2016/21/B/ST7/02241. The results published here are in part based upon data generated by TCGA managed by the NCI and NHGRI. Information about TCGA can be found at http://cancergenome.nih.gov."

should read:

“This project has received funding from the European Union's Horizon 2020 Research and Innovation Programme under grant agreement No. 667403 for HERCULES, the Academy of Finland, the Sigrid Jusélius Foundation, Finnish Cancer Associations and by National Science Centre, Poland (https://ncn.gov.pl), grant DEC 2016/21/B/ST7/02241. The results published here are in part based upon data generated by TCGA managed by the NCI and NHGRI. Information about TCGA can be found at https://cancergenome.nih.gov."

(i) Open Access This article is licensed under a Creative Commons Attribution 4.0 International License, which permits use, sharing, adaptation, distribution and reproduction in any medium or format, as long as you give appropriate credit to the original author(s) and the source, provide a link to the Creative Commons license, and indicate if changes were made. The images or other third party material in this article are included in the article's Creative Commons license, unless indicated otherwise in a credit line to the material. If material is not included in the article's Creative Commons license and your intended use is not permitted by statutory regulation or exceeds the permitted use, you will need to obtain permission directly from the copyright holder. To view a copy of this license, visit http://creativecommons.org/licenses/by/4.0/.

(C) The Author(s) 2020 